Jnl. Soc. Pol. (2022), 1-25 (C) The Author(s), 2022. Published by Cambridge University Press. This is an Open Access article, distributed under the terms of the Creative Commons Attribution licence (https:// creativecommons.org/licenses/by/4.0/), which permits unrestricted re-use, distribution, and reproduction in any medium, provided the original work is properly cited. doi:10.1017/S0047279421001045

\title{
Who should pay for social care for older people in England? Results from surveys of public attitudes to the funding of adult social
}

\section{care}

\author{
RAPHAEL WITTENBERG* (D, SANNA READ**, BOB ERENS***, \\ MARTIN KNAPP*, GERALD WISTOW**, FRANCIS DICKINSON**, \\ EVA CYHLAROVA** AND NICHOLAS MAYS ${ }^{* * *}$
}

*Policy Innovation and Evaluation Research Unit (PIRU), Care Policy and Evaluation Centre (CPEC), London School of Economics and Political Science, UK

${ }^{* *}$ Care Policy and Evaluation Centre (CPEC), London School of Economics and Political Science, UK

*** Policy Innovation and Evaluation Research Unit (PIRU), Department of Health Services Research and Policy, London School of Hygiene and Tropical Medicine, UK

\begin{abstract}
While debate on how best to pay for social care in England continues, information about public attitudes on this issue is limited. We asked representative samples of the public whether care costs for older people should be met by the state, met by the service user or shared between state and user. We used an online survey of people aged 18-75 $(n=3,000)$ and interview survey of people aged 65 and over $(n=466)$. Respondents were given four vignettes (two home care, two residential care) and asked who should pay at different levels of user resources; and how much users should contribute when costs were shared. Fewer than one-fifth of the online sample and one-quarter of the interview sample considered that the state should meet the full costs whatever users' resources; considerably lower proportions believed that users should meet the full costs in all cases. Two-thirds of the online sample and half the interview sample thought costs should be shared. The proportion of costs that users should contribute was relatively low (20-50 per cent, varying by user resources). The study illustrates that public views elicited through vignettes can provide evidence to inform policy on social care funding.
\end{abstract}

Keywords: Social care of older people; long-term care; funding; paying for care; public attitudes; England

\section{Introduction}

The financing of social care has been the subject of a continual debate in England over the last 20 years (Foster 2021). A central issue has been the balance of responsibilities between service users and the state (Wanless et al., 2006; CFCS, 2011). At present, access to publicly funded social care is subject to an assessment of both care needs and financial means (income and savings) (DHSC 2018). The sustainability and fairness of this system have been 
questioned on a number of grounds (Royal Commission on Long Term Care, 1999, CFCS, 2011). Various reforms have been proposed, ranging from free personal care to limited changes to the means test. Concerns have been expressed about the affordability of some options (Prior, 2015, Charlesworth et al., 2021). These concerns are reinforced by the projected increase in the number of older people needing care (Kingston et al., 2018; Kingston et al., 2018a; ONS, 2019); three-quarters of people living in England will require some social care during their life (Forder and Fernández, 2009) and about 10 per cent are likely to use services costing over $£ 100,000$ (CFCS, 2011). None of the earlier proposals has yet been implemented (Foster, 2021), but the Government announced in September 2021 plans to introduce reforms from October 2023 (HM Government, 2021).

An important issue underlying this debate is whether social care should be universal or targeted. A targeted system concentrates resources on those in greatest need of support and who may not otherwise be able to afford care needed to maintain independence and quality of life. Under a universal system, some resources are allocated to people who could afford to fund their own care (fully or partially) without public subsidy (Oorschot, 1999; Townsend, 2002). However, a universal system gives the whole population a stake in the programme, which may increase political support for it, thereby increasing pressure to maintain standards and reduce stigma associated with receipt of public support (Titmuss, 1968). It also avoids administrative complexity, implementation costs and perverse incentives that may arise under means-tested programmes, such as disincentives to save for one's own care (Oorschot, 1999). While it may seem fairer to concentrate resources on those least able to fund their care, there may also be a perception of unfairness where those who have worked and saved are denied access to public funding available to those who have not saved.

The overall issue of public funding for social care entails many considerations, including: sources of funding; how funding is distributed between local commissioners; and the balance between public and private funding. This paper focuses on the balance between public and private funding. It does not extend to questions of taxes or other sources of funding (Sussex et al., 2019), nor to provision of care and care markets (Fernández and Forder, 2015).

Many countries have considered whether to reform their system for funding social care. Public coverage of social care has generally been more limited than health care coverage, and private insurance for social care has faced market failure challenges (Comas-Herrera et al., 2012), leaving people with substantial needs at risk of high lifetime care costs if they require intensive support over extended periods. For example, Scotland introduced free personal care for older people in 2002, and later extended it to adults of all ages (Scottish Government, 2019). Germany introduced a social insurance scheme for long-term care in 
1995 under which publicly funded support is available for those with significant care needs on a universal basis without means test (Curry, 2019). Japan introduced a social insurance scheme in 2000 (Curry et al., 2018). Even with these reforms, service users still contribute to care costs. In Scotland, the means test remains for accommodation costs in care homes and help with domestic tasks in the community. Benefits under the German system are generally not sufficient to fully meet care home fees. In Japan, a small user co-payment is required from those able to afford it. The policy issue which this paper informs is therefore relevant to many countries.

Attempts to understand the public's views on how to pay for social care have been predominantly through qualitative studies (Dixon et al., 2019; Hewitson et al., 2011; Ipsos Mori, 2018; Overton and Fox O'Mahony, 2017; Price et al., 2014) and descriptive surveys (Ipsos Mori, 2013; Tian, 2014; Wood and Vibert, 2017). While most people in England favour health care provision free at point of use and funded through taxation (Burkitt et al., 2018; Ipsos Mori, 2013), surveys about social care funding have generated different findings (Gregory, 2014). For example, one study, conducted in 2013 with 1,005 adults in England, found equal proportions of people (41\%) who agreed and disagreed that the individual had responsibility to pay for their care (Ipsos Mori, 2013). By contrast, half the around 1,000 respondents in another British study thought that government should pay for social care, 27 per cent that individuals should pay up to a capped amount, and 22 per cent that individuals should pay what they could and the government should pay the rest (Tian, 2014). A third survey, conducted in 2017 with 2,120 people across the UK, found that 36 per cent believed that government should pay for social care, 31 per cent that individuals should contribute to their care costs up to a capped amount, and 24 per cent that government should pay only for people with low income and wealth. Only 3 per cent thought that individuals should pay all their care costs (Wood and Vibert, 2017).

Recent studies reveal that most people do not think that their housing assets should be used to fund their old age care (Overton and Fox O'Mahony, 2017), and also that people do not want to rely on unpaid family care (Bottery et al., 2018; Ipsos Mori, 2018).

It is unclear why findings from these surveys vary. Survey context, timing, design, sampling strategy, mode and conduct of data collection, and question wording could all affect findings. The Ipsos MORI survey (2013) covered health and social care and included questions on a wide range of issues, especially user satisfaction with services. The British Social Attitudes Survey (Tian, 2014) covered a wide range of topics including satisfaction with the NHS and social care. The Demos survey (Wood and Vibert, 2017), while including a focus on social care, had a wider remit related to the elements of a good retirement including financial wellbeing. 
Our study differs from previous studies in two main respects. It focuses solely on attitudes to paying for social care rather than asking about social care in the context of a wider study covering health care, pensions or other topics. Second, it uses the novel approach of providing vignettes which specify the typical weekly costs of care and the resources of the service user, rather than asking about attitudes to paying for care in a generalised way.

One challenge with studying attitudes to social care funding is that the public in England has limited understanding of current arrangements, with many believing that care is free at the point of use, similar to the National Health Service (NHS) (Gregory, 2014; Ipsos Mori, 2018; Sussex et al., 2019). Few of those people who do understand that social care is not free appear also to understand the complexity of the means test. In addition, there is limited appreciation of the level of risk of needing care in older age.

Studying public attitudes to social care funding is therefore challenging because the system is unfamiliar and complex to understand for many people, and the topic is often regarded as unpleasant to contemplate (Wood and Vibert, 2017). However, while a very brief explanation of the current system was provided to sample members before the vignettes were presented, our study did not require that survey respondents had detailed knowledge of the current means test.

\section{Current funding arrangements}

Local authorities are responsible for assessing needs for social care of adults living in their area, setting eligibility criteria for publicly funded care, commissioning services and arranging care, mainly from independent providers. Much of this activity is conducted within national frameworks: local authorities are required to take account of national minimum eligibility criteria, a national means test for residential care and national guidelines for means-testing community-based care (DHSC, 2018).

The market for social care consists of a large number of mainly small provider organisations from which both local authorities and individuals purchase care (Curry and Oung, 2021). Local authority support takes the form of a personal budget, reflecting the authority's assessment of the person's needs (DHSC 2018, paragraph 11.7). For community-based care, individuals can choose to request the local authority to arrange care for them or to take a direct payment (a cash payment that the person can use to employ a personal assistant or purchase care) (DHSC 2018, paragraphs 12.1-12.9). The means test does not differ between direct payments and packages of local authority-arranged care.

The means test takes account of both savings and income; and, in the case of residential care, also the value of the person's home (with limited exceptions).

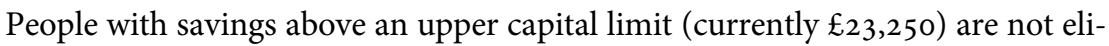
gible for publicly funded care. While savings below a lower capital limit 
(currently $\mathfrak{1 2}_{12,250}$ ) are ignored, savings between the upper and lower limits are considered on a sliding scale. Moreover, people eligible for publicly funded residential care are required to contribute all their income toward the costs of their care except for a relatively low personal allowance ( $\{24.90$ per week). In the case of community-based care, they retain the higher sum of $\mathfrak{E}_{1} 89$ per week to enable them to meet their general living expenses. These provisions mean that some older people, especially those with substantial savings who require care over an extended period, may be required to make large contributions to their care costs. A substantial proportion of people fund their own social care, although little is known about them (Baxter et al., 2019).

The government recently announced introduction in England of a lifetime $£ 86,000$ cap on liability to meet care costs and an increase in the lower and upper capital limits in the means test to $£_{20}, 000$ and $£_{100,000}$, respectively. These reforms will be implemented in October 2023. They will be funded through a new Health and Social Care Levy, which will also fund wider changes to health and social care (HM Government, 2021).

The aim of the study reported in this paper was to provide more detailed, up-to-date quantitative evidence on public attitudes to the balance of funding responsibility between the state and the individual. The purpose was to inform government decisions concerning reform of the funding of social care in England. The central research questions were:

- what are the views of the general public about whether social care costs should be met by the state, met by the service user or shared between them; and

- what are the views of the general public about whether who pays for care should vary with the service user's income and savings?

These questions were addressed by using vignettes of older people needing home care or residential care with different levels of personal financial resources. The vignettes were presented to two representative samples of people in England to elicit their preferences for state and user contributions in paying for social care.

\section{Methods}

\section{Sample}

We conducted two surveys of the general population in England in collaboration with Kantar, which is a data, insights and consulting company whose work includes studies for public sector agencies. The first used the online panel run by the Kantar Profiles Division, which numbers over 150,000 adults. Panel respondents are invited to take part in surveys by email and incentivised with points that they can trade for vouchers. Three thousand people living in England 
aged between 18 and 75 years participated in the online survey for our study. They included an equal number of men and women, with quotas for age based on the population of England. The online survey was administered from 6 to 19 December 2018. Because of evidence of poorer coverage of older people in online surveys (Bethlehem, 2010; Hirsch et al., 2013), we included the same questions on Kantar's continuous face-to-face interview omnibus survey, which we considered would provide a more robust sample than an online survey of an older group. The omnibus survey is carried out weekly among a cross-section of adults aged $16+$ living in private households in the UK. Each survey covers a range of topics. Four hundred and sixty-six individuals aged 65 and over living in England participated in face-to face interviews for our study, between 30 November and 4 December 2018. Survey methods and sample representativeness are detailed elsewhere (Erens et al., 2020).

\section{Variables}

Vignettes were used to elicit preferences on how much the state and the service user should contribute to paying for social care in particular circumstances. Four vignettes were developed based on previous findings from focus groups on people's perceptions and behaviours with respect to planning for future social care needs, and their priorities for how care should be funded (Dixon et al., 2019). The questionnaire is described elsewhere (Erens et al., 2020). The vignettes are briefly described in Table 1 ; the full questionnaire is available from http://piru.lshtm.ac.uk/assets/files/Funding\%2olong-term\%2osocial\%2ocare\% 20-\%2oonline\%2oquestionnaire.pdf.

Two vignettes related to paying for home care and two to paying for residential care. Respondents were asked how they thought the care should be paid for - by the state, the service user, or shared between them - at varying levels of the service user's savings, income and housing wealth. Answers were recoded into five ordinal categories with increasing user contributions:

(a) state pays all;

(b) user contributes but only at the highest levels of assets;

(c) user contributes at the middle level of assets;

(d) user contributes even at the lowest levels of assets; and

(e) user pays all.

For those who answered that the state and the user should share the costs, i.e. responses (b), (c) or (d), there was a further question about the amount the respondent proposed the user should pay.

There was a further scenario where use of home care or residential care continued for 4-5 years and the total cost over those years was given as 
TABLE 1. The four vignettes used to measure the preferences for paying for home care and residential care costs.

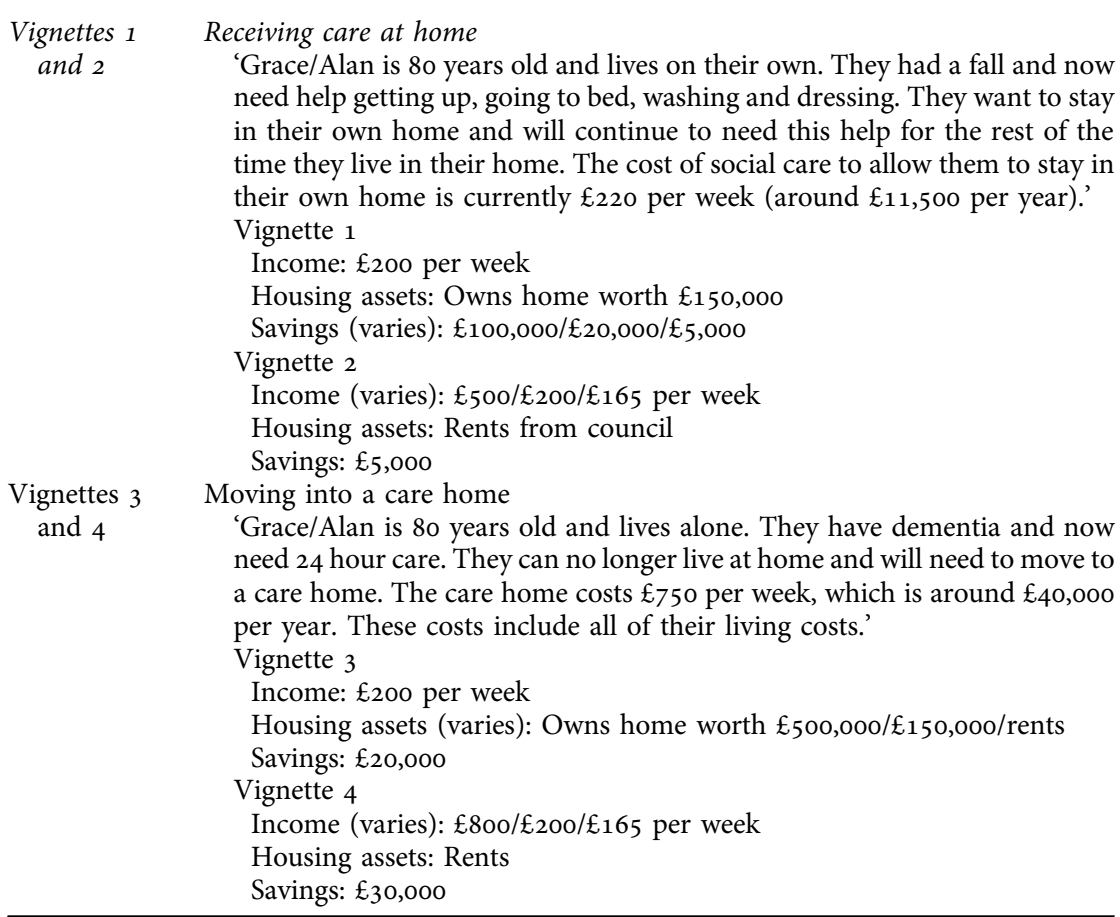

$\mathfrak{£}_{100,000}$ for home care and $\mathfrak{£}_{160,000}$ for residential care. For those who answered that the state should pay all the cost, a further question asked if there was a level of service user savings above which the user should contribute to the cost. For those who responded that the user should pay all the cost, a further question asked whether there was any upper limit above which the state should take over meeting the costs.

The scenarios on paying for home care and residential care costs were identical for all respondents, except that a randomly selected half of respondents received a vignette with a female character (named Grace in the questionnaire) and the other half with a male character (named Alan) for the first two vignettes on home care. In the second two vignettes related to residential care, the names of the vignette characters were swopped over so that each respondent had two vignettes of male and two vignettes of female characters in a random starting order. We investigated the effect of vignette gender on the vignette responses. 


\section{Sociodemographic characteristics}

A binary variable for gender $(0=$ male, $1=$ female $)$ was used. Three age groups were created in each sample: younger respondents $(1=18-34$ years $)$, middle aged ( $2=35-64$ years $)$ and older people $(3=65-75$ years $)$ in the online sample; and early old age $(1=65-74$ years $)$, aged 75 to 84 years $(2=75-84)$, and late old age $(3=85$ years or above) in the interview sample. Having a partner was a binary variable $(0=$ no, $1=$ yes $)$. Education was measured at three levels: $1=$ no qualifications, $2=$ upper secondary education, and $3=$ higher education.

Social grade was measured using the National Readership Survey (NRS) classification of the occupation of the chief income earner in the household. It relates to the person's current job or, if retired, to their previous job, with those retired people who never worked or worked so little that they receive state pension only included in the lowest category. Social grade is coded into three categories:

- higher (categories A and B; higher or intermediate managerial, administrative and professional),

- intermediate (categories $\mathrm{C}_{1}$ and $\mathrm{C}_{2}$; supervisory, clerical and junior managerial, administrative and professional, and skilled manual workers), and

- lower (categories D and E; semi-skilled and unskilled manual workers, state pensioners, casual and lowest-grade workers, not employed with state benefits only including homemakers and students).

Housing tenure status and house value were combined into a five-category

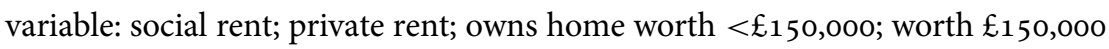
to 499,999 ; and worth $>£ 499,999$.

\section{Analysis}

We used cross-tabulations to show the distributions of responses, as the vignette variables were a mixture of ordered categorical categories (state paying all to user paying all) and binary categories ('Don't know' versus providing a response; and 'yes' versus 'no' answers to some follow-on questions). Medians were used for the amount paid by the user when the cost was shared between user and state, and for the levels of savings when the user started to contribute and the upper limit when the state started to contribute. To investigate differences in attitudes towards paying for home care versus residential care costs, we selected vignettes 1 and 3 which used the same type of asset (levels of income) in paying for home care (vignette 1 ) and residential care (vignette 3 ) costs.

We used ordered logit regression to analyse data from these particular vignettes to identify any differences in attitudes towards paying for home care versus residential care costs. Ordered logit regression was used because the 
dependent variable, paying for residential care, has ordinal categories. The original five categories were reduced to three $(1=$ state pays all, $2=$ shared, combining sharing the cost at the lowest, middle and highest levels of income, and $3=$ individual pays all) for simplicity. Paying for home care was used as a predictor. The middle level of income was used for both paying for home care and residential care costs. The model was adjusted for gender, age, having a partner, educational level, social grade and tenure/house value which are known to be associated with preferences for paying for social care (Read et al., 2021). The samples were not weighted. Predicted margins from this model were then used in a cross-tabulation to illustrate the patterns of preferences for paying for home care versus residential care costs.

To investigate the effect of the vignette character's gender, we carried out an ordered logit regression using vignette gender (female or male character) as a predictor and the three ordinal categories $(1=$ state pays all, $2=$ costs shared, 3 = individual pays all) in each vignette as an outcome. The models were adjusted for gender, age, having a partner, educational level, social grade and tenure/house value. Predicted margins from this model were used to illustrate the patterns of preferences for paying for home care and residential care costs by vignette gender.

\section{Ethics}

The surveys were approved by the London School of Hygiene and Tropical Medicine Observational Research Ethics Committee (Ref 16186). They were conducted by Kantar, using their established online panel and omnibus surveys. The data provided by Kantar to the research team were anonymised.

\section{Results}

\section{Sample sociodemographic characteristics}

Most of the people in the online sample were aged between 35 and 64 years ( 54 per cent) and in the interview sample between 65 and 75 years ( 56 per cent; Table 2). Ninety-one percent of the online sample and 95 per cent of the interview sample identified themselves as white. About a third of the online and a fifth of the interview sample were in an occupation coded as higher social grade. In the online sample, 17 per cent rented their home from local authorities and 19 per cent rented privately, whereas the respective figures for the interview sample were 20 per cent and 4 per cent. Forty-two per cent of the online sample had a degree, more than half (53\%) had qualifications below degree level and only a small proportion $(5 \%)$ had no formal qualifications. Of the interview sample, $23 \%$ had a degree, $38 \%$ qualifications below degree level and 39\% no formal qualifications. Although the achieved samples were largely representative of the relevant population in England on most demographic characteristics, such 
TABLE 2. Distributions of the sociodemographic characteristics in the two samples, per cent.

\begin{tabular}{|c|c|c|c|c|}
\hline \multirow[b]{2}{*}{ Variable } & \multicolumn{2}{|c|}{$\begin{array}{l}\text { Online sample aged } \\
18-75\end{array}$} & \multicolumn{2}{|c|}{$\begin{array}{l}\text { Interview sample } \\
\quad \text { aged } 65+\end{array}$} \\
\hline & $n$ & $\%$ & $n$ & $\%$ \\
\hline Gender (female) & 3,000 & 50.0 & 466 & 49.8 \\
\hline Age group & 3,000 & & 466 & \\
\hline $18-34$ & & 32.0 & & - \\
\hline $35-64$ & & 54.0 & & - \\
\hline $65-74^{a}$ & & 14.0 & & 55.6 \\
\hline $75-84$ & & - & & 31.8 \\
\hline $85+$ & & - & & 12.7 \\
\hline Partner & 2,965 & 60.8 & 466 & 55.2 \\
\hline Education & 2,965 & & 466 & \\
\hline No qualification & & 4.9 & & 38.7 \\
\hline Upper secondary & & 53.0 & & 38.5 \\
\hline Higher & & 42.1 & & 22.8 \\
\hline Social grade & 3,000 & & 466 & \\
\hline Lower (DE) & & 23.1 & & 37.6 \\
\hline Intermediate $\left(\mathrm{C}_{1} \mathrm{C}_{2}\right)$ & & 43.2 & & 39.1 \\
\hline Higher (AB) & & 33.7 & & 23.4 \\
\hline Tenure/house value & 2,870 & & 466 & \\
\hline Rents, Local Authority & & 17.1 & & 20.2 \\
\hline Rents, private & & 18.9 & & $3 \cdot 9$ \\
\hline Owns house, $<\mathfrak{E} 150,000$ & & 21.0 & & $33 \cdot 7$ \\
\hline Owns house, $£ 150,000-499,999$ & & 36.5 & & 36.9 \\
\hline Owns house, $\mathfrak{E}_{500,000+}$ & & 6.5 & & 5.4 \\
\hline
\end{tabular}

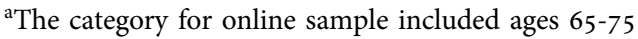

as age, marital status and region, there was a slight over-representation of those with higher education in the online sample. Further information about sample characteristics is available in Erens et al. (2020).

\section{Descriptive results on paying for care costs}

Distributions of responses to the four vignettes varied between both vignettes and samples (Table 3; Figure 1). Fewer than one-fifth of the online sample and around one-quarter of the interview sample considered that the state should meet the full costs of care whatever the service user's resources. Considerably lower proportions believed that the service user should meet the full costs in all cases. Around two-thirds of the online sample and half of the interview sample thought that costs should be shared between state and user.

For residential care, around 40 per cent of the online sample and 30 per cent of the interview sample considered that the user should contribute to their care costs even at low levels of resources. For home care, rather lower proportions 
TABLE 3. Distributions of the vignette responses (\%) on paying for home care and residential care costs in the two samples.

\begin{tabular}{|c|c|c|c|c|}
\hline & $\begin{array}{l}\text { Vignette } \\
\text { 1: home } \\
\text { care }^{\mathrm{a}}\end{array}$ & $\begin{array}{l}\text { Vignette } \\
\text { 2: home } \\
\text { care }^{\mathrm{b}}\end{array}$ & $\begin{array}{l}\text { Vignette 3: } \\
\text { residential } \\
\text { care }^{c}\end{array}$ & $\begin{array}{l}\text { Vignette } 4: \\
\text { residential } \\
\text { care }^{\mathrm{d}}\end{array}$ \\
\hline & $\%$ & $\%$ & $\%$ & $\%$ \\
\hline \multicolumn{5}{|l|}{$\begin{array}{l}\text { Online sample aged } 18-75 \\
\quad(n=3,000)\end{array}$} \\
\hline State pays all (full cost) in all cases & 14.0 & 20.0 & 16.2 & 15.2 \\
\hline $\begin{array}{l}\text { Cost shared only at the highest level } \\
\text { of income/savings/housing }\end{array}$ & $14 \cdot 3$ & 36.4 & 7.4 & $9 \cdot 3$ \\
\hline Cost shared at the middle level & 27.6 & $19 \cdot 3$ & 22.9 & 16.4 \\
\hline Cost shared even at the lowest level & 26.0 & 12.6 & 39.0 & 39.8 \\
\hline User pays all (full cost) in all cases & 11.2 & 5.2 & 6.4 & 11.7 \\
\hline I don't know & 6.9 & 6.4 & 8.1 & 7.6 \\
\hline \multicolumn{5}{|l|}{$\begin{array}{l}\text { Interview sample aged } 65+ \\
\quad(n=466)\end{array}$} \\
\hline State pays all (full cost) in all cases & 23.2 & 25.9 & 20.0 & $19 \cdot 3$ \\
\hline $\begin{array}{l}\text { Cost shared only at the highest level } \\
\text { of income/savings/housing }\end{array}$ & 15.4 & 23.9 & $7 \cdot 3$ & $9 \cdot 3$ \\
\hline Cost shared at the middle level & $19 \cdot 3$ & 15.4 & 17.4 & 10.4 \\
\hline Cost shared even at the lowest level & 17.0 & 11.2 & 30.5 & 27.0 \\
\hline User pays all (full cost) in all cases & 9.7 & 3.1 & 3.5 & $7 \cdot 3$ \\
\hline I don't know & 15.4 & 20.5 & 21.1 & 26.6 \\
\hline
\end{tabular}

${ }^{a}$ Vignette 1: paying for home care cost of $\mathfrak{2}_{22}$ /week at varying levels of savings

${ }^{b}$ Vignette 2: paying for home care cost of $\mathfrak{2}_{22}$ /week at varying levels of income

${ }^{c}$ Vignette 3: paying for residential care cost of $\mathfrak{E}_{75}$ /week at varying levels of house value

${ }^{d}$ Vignette 4: paying for residential care cost of $\mathfrak{E}_{75}$ o/week at varying levels of income

believed that the user should contribute even at low levels of resources. However, as explained below, similar views were held about paying for home care and for care home costs when the residential care and home care users had the same resources. The online sample was more likely than the interview sample to consider that the user should contribute to the costs of their care. The proportions of 'don't know' answers varied by scenario: between 7 and 8 per cent in the online sample and between 15 and 27 per cent in the interview sample.

Sample members were asked what proportion of the total cost the service user should contribute where costs were shared between state and user. Both the online sample and the interview sample reported similar preferences. For the home care vignettes, respondents thought that users with low levels of savings or income should contribute between 22 and 25 per cent of the cost of care as set out in the vignettes, rising to 45 to 50 per cent for those with high savings or incomes (Table 4). Similarly, for residential care, those with low levels of housing wealth or income should contribute between 20 and 25 per cent of the cost of 
(A)

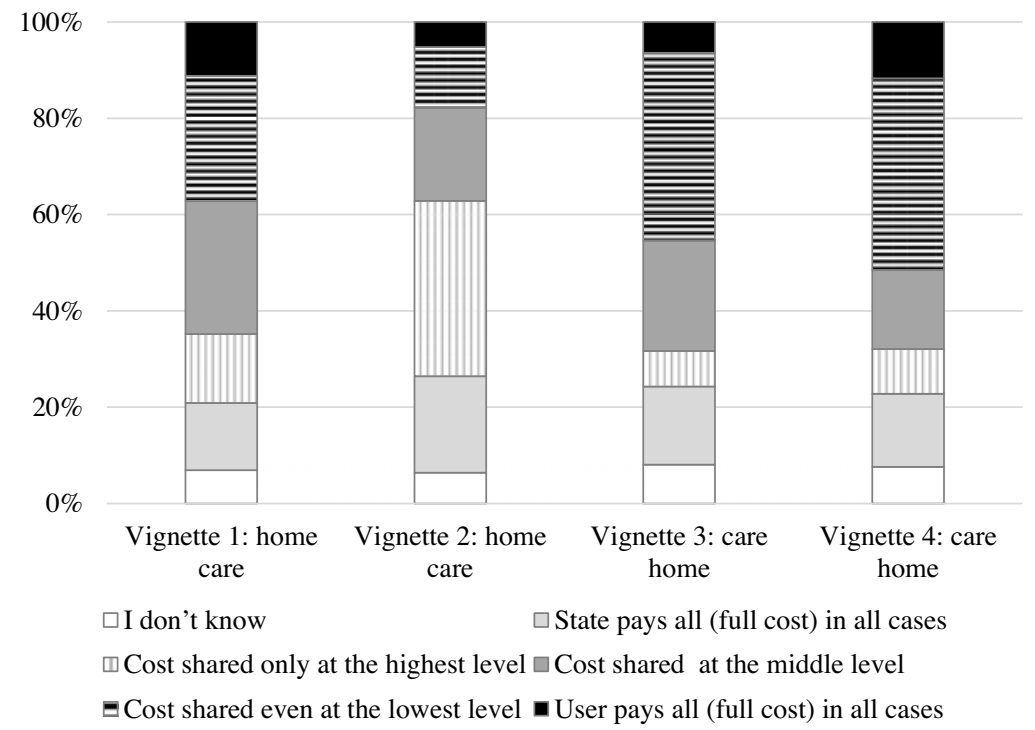

(B)

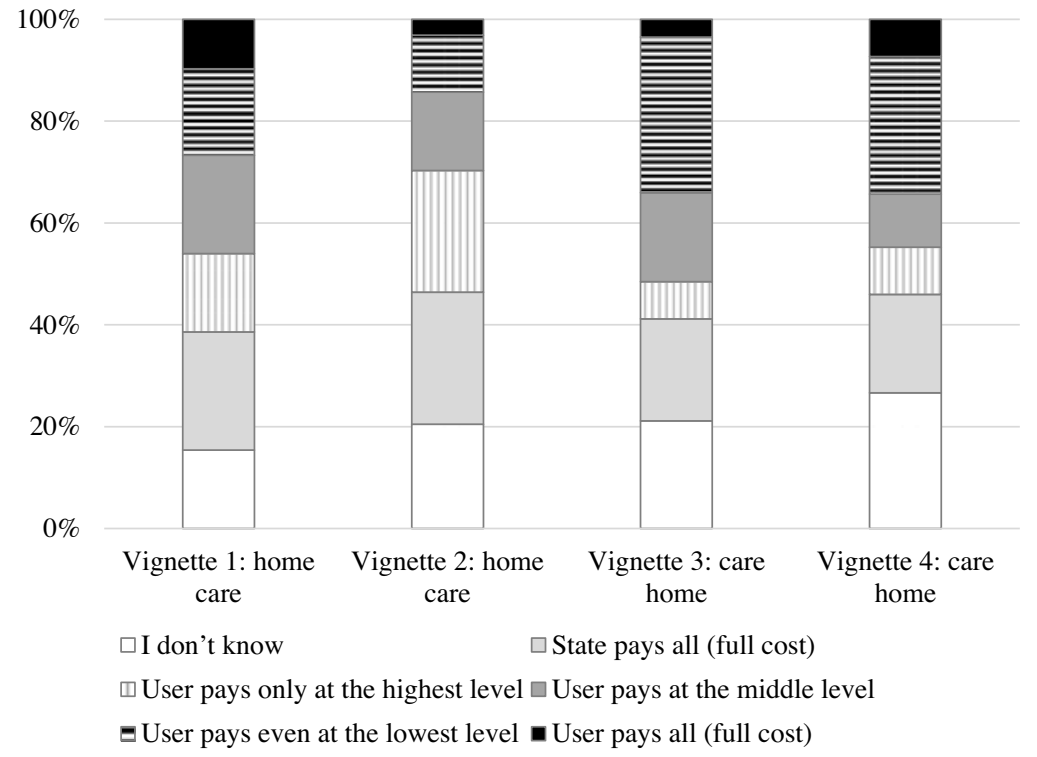

Figure 1. A. The distributions of the vignette responses (\%) on paying for home care and residential care costs in the online sample. B. The distributions of the vignette responses (\%) on paying for home care and residential care costs in the interview sample. 
TABLE 4. The medians of how much the user should contribute when the cost is shared between the state and the user in the two samples.

\begin{tabular}{|c|c|c|c|c|}
\hline & $\begin{array}{l}\text { Vignette } 1 \text { : } \\
\text { home care } \\
\text { cost of } \mathfrak{E} 220 /^{2} \\
\text { week }^{\text {a }}\end{array}$ & $\begin{array}{l}\text { Vignette 2: } \\
\text { home care } \\
\text { cost of } \mathfrak{E}_{220} \text { / } \\
\text { week }^{b}\end{array}$ & $\begin{array}{l}\text { Vignette 3: resi- } \\
\text { dential care cost } \\
\text { of } £_{750} / \text { week }^{c}\end{array}$ & $\begin{array}{l}\text { Vignette 4: resi- } \\
\text { dential care cost } \\
\text { of } £ 750 / \text { week }^{d}\end{array}$ \\
\hline \multicolumn{5}{|l|}{$\begin{array}{l}\text { Online sample aged } 18 \text { - } \\
\quad 75(n=3,000)\end{array}$} \\
\hline $\begin{array}{l}\text { User contributes even } \\
\text { at the low level of } \\
\text { income/savings/ } \\
\text { housing }\end{array}$ & $\mathfrak{E}_{50}$ & $\mathfrak{E}_{55}$ & 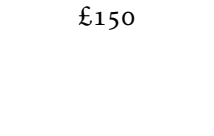 & $\mathfrak{E}_{150}$ \\
\hline $\begin{array}{l}\text { User contributes at the } \\
\text { middle level }\end{array}$ & $\mathfrak{E}_{100}$ & $\mathfrak{E}_{50}$ & $£_{200}$ & $\mathfrak{E}_{175}$ \\
\hline $\begin{array}{l}\text { User contributes only } \\
\text { at the high level }\end{array}$ & $£_{100}$ & $£_{110}$ & $\mathfrak{E}_{200}$ & $\mathfrak{E}_{325}$ \\
\hline \multicolumn{5}{|l|}{$\begin{array}{l}\text { Interview sample aged } \\
65+(n=466)\end{array}$} \\
\hline $\begin{array}{l}\text { User contributes even } \\
\text { at the low level of } \\
\text { income/savings/ } \\
\text { housing }\end{array}$ & $\mathfrak{E}_{55}$ & $\mathfrak{E}_{50}$ & $£_{190}$ & $\mathfrak{E}_{150}$ \\
\hline $\begin{array}{l}\text { User contributes at the } \\
\text { middle level }\end{array}$ & $£ 100$ & $\mathfrak{E}_{53}$ & $£_{200}$ & $£_{200}$ \\
\hline $\begin{array}{l}\text { User contributes only } \\
\text { at the high level }\end{array}$ & $£ 100$ & $£_{110}$ & $£_{225}$ & $\mathfrak{E}_{388}$ \\
\hline
\end{tabular}

${ }^{a}$ Vignette 1: paying for home care cost of $\mathfrak{2}_{22}$ /week at varying levels of savings

${ }^{b}$ Vignette 2: paying for home care cost of $\mathfrak{2}_{22}$ /week at varying levels of income

${ }^{c}$ Vignette 3: paying for residential care cost of $\mathfrak{£}_{75}$ /week at varying levels of house value

${ }^{d}$ Vignette 4: paying for residential care cost of $£_{750}$ /week at varying levels of income

care, rising to between 43 and 51 per cent for those with high housing wealth or income (Table 4). The proportions of 'don't know' answers in the home care vignettes varied between 12 and 18 per cent in the online sample and between 20 and 29 per cent in the interview sample. These proportions were somewhat higher in the residential care vignettes: 18 to 25 per cent in the online sample and 23 to 33 per cent in the interview sample.

In both samples, the majority of those who proposed that the state should meet the full cost of care held this view irrespective of service user's income, savings or housing wealth (Table 5). Among the minority who answered that there should be a level of resources above which the user starts to contribute, the levels were generally high: $\mathfrak{2}_{250}$,000 savings and income of $£ 800$ per week for home care, and $\mathfrak{E}_{1}$ million housing wealth and income of $\mathfrak{}_{1}$, ooo per week for residential care in the online sample. Because of very small numbers and a higher proportion of 'don't know' answers, the median levels could not be reliably calculated for the interview sample. 
TABLE 5. For those responding "state pays all", whether there is any level of income, savings or house value above which the service user should contribute and, if so, what level

For those responding "state pays all": whether there is any level of savings, income or house value above which the service user should contribute?

\begin{tabular}{|c|c|c|c|c|}
\hline & & No $(\%)^{\mathrm{a}}$ & Yes $(\%)^{\mathrm{a}}$ & Don't know (\%) \\
\hline $\begin{array}{l}\text { Online sample a } \\
\text { Interview sample } \\
\text { If answered "yes } \\
\text { above what level }\end{array}$ & $\begin{array}{l}(n=300-480) \\
-(n=84-112) \\
\text { gs, income or } \mathrm{l}\end{array}$ & $\begin{array}{l}\text { 63-77 } \\
64-79 \\
\text { value sho }\end{array}$ & $\begin{array}{c}13-21 \\
7-16\end{array}$ & $\begin{array}{c}4-9 \\
14-20 \\
\end{array}$ \\
\hline Paying for & Type of asset & $\mathrm{Mec}$ & & Don't know (\%) \\
\hline Home care & Savings & $\mathfrak{E} 25$ & & 7 \\
\hline Home care & Income & $£ 80$ & & 7 \\
\hline Residential care & House value & $\mathfrak{E}_{1} \mathrm{r}$ & & 9 \\
\hline Residential care & Income & $\mathfrak{E}_{1,0}$ & week & 4 \\
\hline
\end{tabular}

${ }^{\text {aThe }}$ range of $\%$ over the four vignettes.

$b_{\text {in }}$ online sample aged $18-75(n=54-117)$ only: not calculated for the interview sample because the numbers were small and contained many 'don't know' answers.

Among those who responded that the user should pay all the costs, only 5 to 18 per cent (over the four vignettes) in the online sample and 4 to 21 per cent in the interview sample stated that there should not be any upper limit to users' liability to meet the costs of care (Table 6). Among the majority who answered that there should be an upper limit, the limits suggested were generally rather low. In the online sample, the median levels were a $\mathfrak{E}_{15}$,000 savings limit for home care and a $£ 20$,ooo housing wealth limit for residential care. The median limits suggested by the interview sample were considerably higher. However, almost half of the online sample and 40 per cent of the interview sample answered 'don't know' to this question.

\section{Comparison of paying for home care versus residential care}

We compared people's views on funding of home care with their views on funding of care home costs. Vignette 1 (home care) can be compared with vignette 3 (care home) since both relate to a person who has an income of

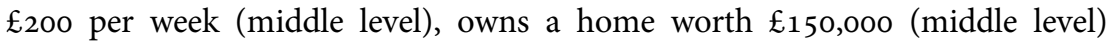
and has savings of $£_{20,000}$ (middle level). The ordered logit model in Table 7 shows high stability in the views on funding home care versus residential care. Respondents who proposed that an individual should pay all home care costs were likely to propose that the individual should pay all residential care costs too. Table 8 shows the predicted margins from the ordered logit model 
TABLE 6. For those responding "user pays all/some", whether there should be an upper limit to user contributions from income, savings or housing wealth and if so what should be the upper limit

For those responding "user pays all/some": should there be any upper limit to user contribution from savings, income or housing wealth?

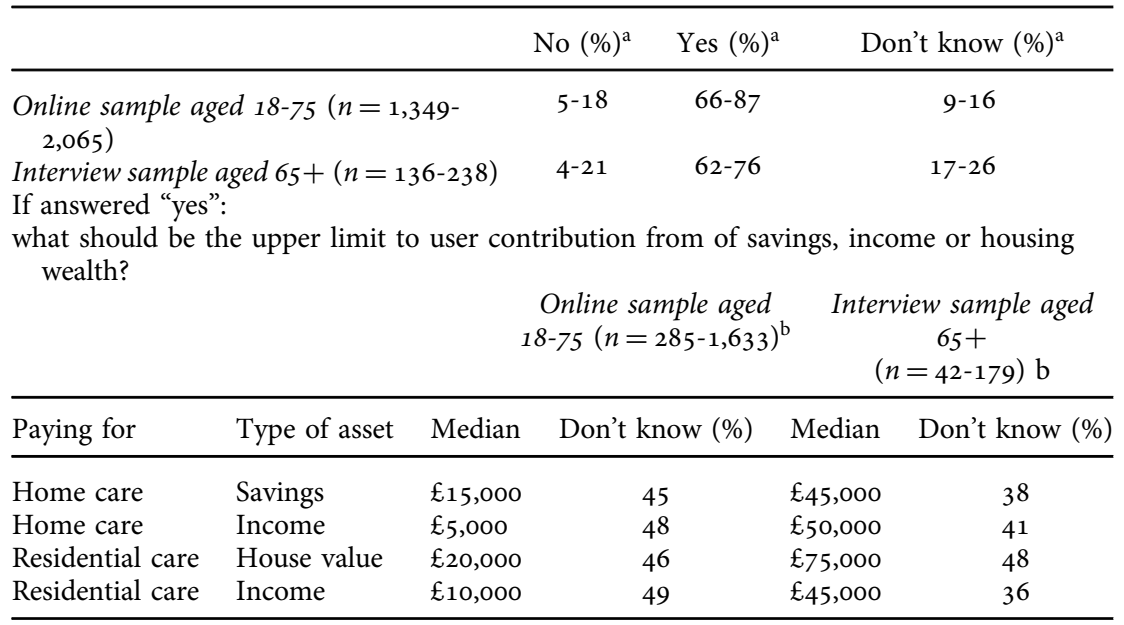

${ }^{a}$ The range of $\%$ over the four vignettes.

${ }^{\mathrm{b}}$ The variation in $\mathrm{n}$ due to different levels used for follow-on questions in different vignettes.

to illustrate the proportions in each category. Of those in the online survey who considered that the state should pay for all home care ( $27 \%$ of the sample), $61 \%$ considered that the state should also pay for all residential care and almost all the rest $(37 \%)$ felt that the cost should be shared between the state and the individual (Table 8). Similarly, of those who considered that the individual should pay for all home care ( $18 \%$ of the sample), $61 \%$ considered that the individual should pay for all residential care and almost all the rest $(36 \%)$ felt that the cost should be shared. Two-thirds (67\%) of those who considered that the costs of home care should be shared ( $55 \%$ of the sample) held the same view for care home costs, with $14 \%$ considering that the state should meet all the costs of residential care and $19 \%$ that the individual should meet all of them. This suggests that fairly similar views were held about paying for home care and for care home costs where the service user has modest income and savings and owns a home of below average value. Among those who proposed that home care costs be shared between the individual and the state but care home costs should not be shared, there was a slight preference for the individual rather than the state to meet care home costs (19\% vs. 14\%). Findings were similar for the interview sample of people aged over 65 . 
TABLE 7. Ordered logit regression on preferences for paying for residential care (vignette 3 , ordered categories $1=$ state pays, $2=$ shared, $3=$ individual pays) predicted by preferences for paying for home care (vignette 1 ) at middle level assets and income, adults aged 18-75 $(n=2,546)$ (estimated margins derived from this model shown in Table 8)

(Individual) Paying for residential care at middle level (Vignette 3) Coefficient (Standard Error)

\begin{tabular}{|c|c|}
\hline \multicolumn{2}{|l|}{$\begin{array}{l}\text { Paying for home care at middle level } \\
\text { (Vignette 1) (ref= state pays) }\end{array}$} \\
\hline Shared & $2.24(0.11)^{* * *}$ \\
\hline Individual pays & $4.20(0.15)^{* * *}$ \\
\hline Female & $0.05(0.08)$ \\
\hline \multicolumn{2}{|l|}{ Age group $(\mathrm{ref}=18-34)$} \\
\hline $35-64$ & $0.20(0.10)^{*}$ \\
\hline $65-75$ & $0.10(0.14)$ \\
\hline Has partner & $-0.02(0.09)$ \\
\hline \multicolumn{2}{|l|}{ Education (ref = No qualification) } \\
\hline Upper secondary & $0.01(0.21)$ \\
\hline Higher & $0.13(0.22)$ \\
\hline \multicolumn{2}{|l|}{ Social grade $(\mathrm{ref}=\operatorname{Higher}(\mathrm{AB})$} \\
\hline Intermediate $\left(\mathrm{C}_{1} \mathrm{C}_{2}\right)$ & $-0.03(0.10)$ \\
\hline Lower (DE) & $0.05(0.13)$ \\
\hline \multicolumn{2}{|l|}{$\begin{array}{l}\text { Housing tenure status/house value } \\
\text { (ref = Rents, Local Authority) }\end{array}$} \\
\hline Rents, private & $-0.04(0.15)$ \\
\hline 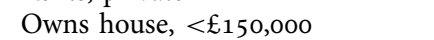 & $-0.19(0.14)$ \\
\hline Owns house, $£ 150,000-499,999$ & $-0.19(0.14)$ \\
\hline Owns house, $£_{500,000+}$ & $0.09(0.21)$ \\
\hline
\end{tabular}

\section{The effect of vignette character's gender}

Overall, the distributions of responses to the four vignettes by vignette gender were similar; however, in both samples, respondents suggested lower payments for the female character (Grace) compared to the male (Alan) in paying for home care costs in vignette 2 (Tables 9 and 10). The estimated margins from the models for vignette 2 showed that a higher proportion, $19 \%$ (95\% CI $16.7 ; 20.6)$ of the online and $35 \%(95 \%$ CI $28.5 ; 41.3)$ of the interview sample, proposed that the state should pay all home care costs for the female character (Grace) while the respective proportions for the male character (Alan) were lower, at $15 \%(95 \% \mathrm{CI} 14.1 ; 16.9)$ and $29 \%(95 \% \mathrm{CI} 22.3 ; 34.8)$. When analysing the vignette gender differences in each of the vignettes for varying levels of income separately, differences were apparent at the lowest $\left(£_{165} /\right.$ week $)$ and middle ( $£ 200 /$ week) levels of income, but not at the highest level of income ( $\mathfrak{E}_{500}$ or $\mathfrak{£} 800 /$ week; results not shown). 
TABLE 8. Cross-tabulation of responses to vignette 3 (home care) and vignette 1 (residential care) at middle level of assets and income, percent (95\% Confidence Interval) using predicted margins from multi-variable analysis (shown in Table 7), adults aged 18-75 $(n=2,534)$

\begin{tabular}{|c|c|c|c|c|}
\hline & \multicolumn{4}{|l|}{ Residential care } \\
\hline & State pays & Shared & Individual pays & Total \\
\hline \multicolumn{5}{|l|}{ Home care } \\
\hline State pays & $\begin{array}{c}60.8 \\
(57.1 ; 64.5)\end{array}$ & $\begin{array}{c}36.7 \\
(33.4 ; 40.1)\end{array}$ & $\begin{array}{c}2.4 \\
(1.9 ; 3.0)\end{array}$ & 100.0 \\
\hline Shared & $\begin{array}{c}14.3 \\
(12.6 ; 16.1)\end{array}$ & $\begin{array}{c}66.7 \\
(64.5 ; 68.9)\end{array}$ & $\begin{array}{c}19.0 \\
(17.0 ; 20.9)\end{array}$ & 100.0 \\
\hline Individual pays & $\begin{array}{c}2.4 \\
(1.8 ; 3.0)\end{array}$ & $\begin{array}{c}36.2 \\
(32.1 ; 40.2)\end{array}$ & $\begin{array}{c}61.4 \\
(56.9 ; 66.0)\end{array}$ & 100.0 \\
\hline
\end{tabular}

Vignette 1 and 3 (middle level): Income: $£ 200$ per week, Housing assets: Owns home worth $\mathfrak{£}_{150,000}$, Savings: $\mathfrak{£}_{20}, 000$. The proportions shown are predicted margins from the ordered logistic regression for the association between paying for home care and paying for residential care adjusted for the respondent's gender, age, having partner, educational level, social grade and tenure/house value.

\section{Discussion}

We explored the preferences for paying for care in old age of a representative sample of adults in England using vignettes. This approach was chosen to make the complicated topic of social care funding more approachable and standardised between respondents (Erens et al., 2020). The majority of survey respondents believed that responsibility for care costs should be shared between the state and service user. Fewer than one-quarter thought the state should meet the full costs whatever the service user's resources, and a considerably lower proportion believed that the service user should meet full costs in all cases.

Unlike attitudes towards paying for health care, where user fees have not been popular among the public in England (Charlesworth and Johnson 2018), about three-quarters of respondents in our surveys thought that the user should contribute at least partially towards their old age care, albeit with modest levels of contribution, lower than is currently the case. While there were differing views about the share to be met by the user, it was generally less than half the cost of care and often only around one quarter of the cost. Previous studies which did not use vignettes have shown that about half of the public would be willing to contribute directly to their social care costs (Gregory, 2014; Ipsos Mori, 2013; Tian, 2014; Wood and Vibert, 2017) but, compared to our study, larger proportions ( 36 per cent and 48 per cent) of previous samples thought that the government should pay for all social care (Tian, 2014; Wood and Vibert, 2017). In addition, between 3 and 11 per cent of our samples 
TABLE 9. Ordered logit regressions on preferences for paying for social care (ordered categories $1=$ state pays, $2=$ shared, $3=$ individual pays) predicted by vignette gender and respondent characteristics, adults aged 18-75

\begin{tabular}{|c|c|c|c|c|}
\hline & $\begin{array}{l}\text { Vignette } 1 \text { : } \\
\text { home care } \\
(n=2,566)\end{array}$ & $\begin{array}{l}\text { Vignette } 2 \text { : } \\
\text { home care }{ }^{\mathrm{b}} \\
(n=2,549)\end{array}$ & $\begin{array}{c}\text { Vignette 3: } \\
\text { residential } \\
\text { care }^{\mathrm{c}} \\
(n=2,524)\end{array}$ & $\begin{array}{l}\text { Vignette } 4: \\
\text { residential } \\
\text { care }^{\mathrm{d}} \\
(n=2,522)\end{array}$ \\
\hline Vignette gender female & $-0.05(0.10)$ & $-0.24(0.11)^{*}$ & $0.06(0.07)$ & $-0.01(0.08)$ \\
\hline $\begin{array}{l}\text { Respondent characteristics } \\
\text { Female }\end{array}$ & $0.21(0.11)^{*}$ & $0.13(0.11)$ & $0.21(0.08)^{* *}$ & $0.17(0.08)^{*}$ \\
\hline $\begin{array}{l}\text { Age group }(\mathrm{ref}=18-34) \\
35-64\end{array}$ & $-0.35(0.08)^{* * *}$ & $-0.68(0.09)^{* * *}$ & $0.02(0.09)$ & $0.06(0.09)$ \\
\hline $65-75$ & $-0.56(0.12)^{* * *}$ & $-1.02(0.13)^{* * *}$ & $-0.13(0.13)$ & $0.06(0.13)$ \\
\hline Has partner & $0.01(0.08)$ & $-0.01(0.08)$ & $-0.09(0.08)$ & $0.02(0.08)$ \\
\hline \multicolumn{5}{|l|}{$\begin{array}{c}\text { Education (ref }=\mathrm{No} \\
\text { qualification) }\end{array}$} \\
\hline Upper secondary & $-0.04(019)$ & $-0.06(0.19)$ & $0.08(0.19)$ & $0.35(0.19)$ \\
\hline Higher & $0.03(0.20)$ & $0.01(0.20)$ & $0.17(0.19)$ & $0.34(0.19)$ \\
\hline \multicolumn{5}{|l|}{$\begin{array}{l}\text { Social grade }(\mathrm{ref}=\text { Higher } \\
\text { (AB) }\end{array}$} \\
\hline Intermediate $\left(\mathrm{C}_{1} \mathrm{C}_{2}\right)$ & $-0.04(0.09)$ & $-0.15(0.09)$ & $-0.13(0.09)$ & $-0.03(0.09)$ \\
\hline Lower (DE) & $-0.13(0.12)$ & $-0.29(0.12)^{*}$ & $-0.13(0.12)$ & $-0.06(0.12)$ \\
\hline \multicolumn{5}{|l|}{$\begin{array}{l}\text { Housing tenure status/ } \\
\text { house value (ref= } \\
\text { Rents, Local Authority) }\end{array}$} \\
\hline Rents, private & $0.04(0.13)$ & $0.09(0.13)$ & $0.10(0.13)$ & $0.05(0.13)$ \\
\hline Owns house, $<\mathfrak{E}_{150,000}$ & $-0.07(0.13)$ & $0.18(0.13)$ & $0.12(0.13)$ & $0.21(0.13)$ \\
\hline Owns house, $\mathfrak{E}_{150,000-}$ & $0.04(0.12)$ & $0.31(0.13)^{*}$ & $0.09(0.12)$ & $0.23(0.12)$ \\
\hline $\begin{array}{l}499,999 \\
\text { Owns house, } £_{500,000+}\end{array}$ & $0.43(0.19)^{*}$ & $1.04(0.19)^{* * * *}$ & $0.40(0.19)^{*}$ & $0.78(0.20)^{* * *}$ \\
\hline
\end{tabular}

${ }^{a}$ Vignette 1: paying for home care cost of $£_{22}$ /week at varying levels of savings ${ }^{b}$ Vignette 2: paying for home care cost of $£_{22}$ /week at varying levels of income ${ }^{c} V$ ignette 3: paying for residential care cost of $\mathfrak{E}_{75}$ /week at varying levels of house value ${ }^{\mathrm{d}}$ Vignette 4 : paying for residential care cost of $\mathfrak{E}_{750}$ /week at varying levels of income ${ }^{*} p<0.05$, ** $p<0.01,{ }^{* * *} p<0.001$

thought that the user should pay all care costs, compared to only 1 per cent and 3 per cent in previous studies (Tian, 2014; Wood and Vibert, 2017).

Nonetheless, respondents who believed that the costs of care should be shared between state and service user mostly considered that the state should meet the majority of the costs (between 50 per cent and 75 per cent, depending on vignette). Most of those who proposed that 'state pays all' believed that there should not be any levels of savings, income or house value above which the user should be asked to contribute. However, most of those who proposed that 'user pays all/some' believed that there should be an upper lifetime limit on the user's liability to meet care costs, which is consistent with previous studies (Tian, 2014; Wood and Vibert, 2017). 
TABLE 10. Ordered logit regressions on preferences for paying for social care (ordered categories $1=$ state pays, $2=$ shared, $3=$ individual pays) predicted by vignette gender and respondent characteristics, adults aged $65+$

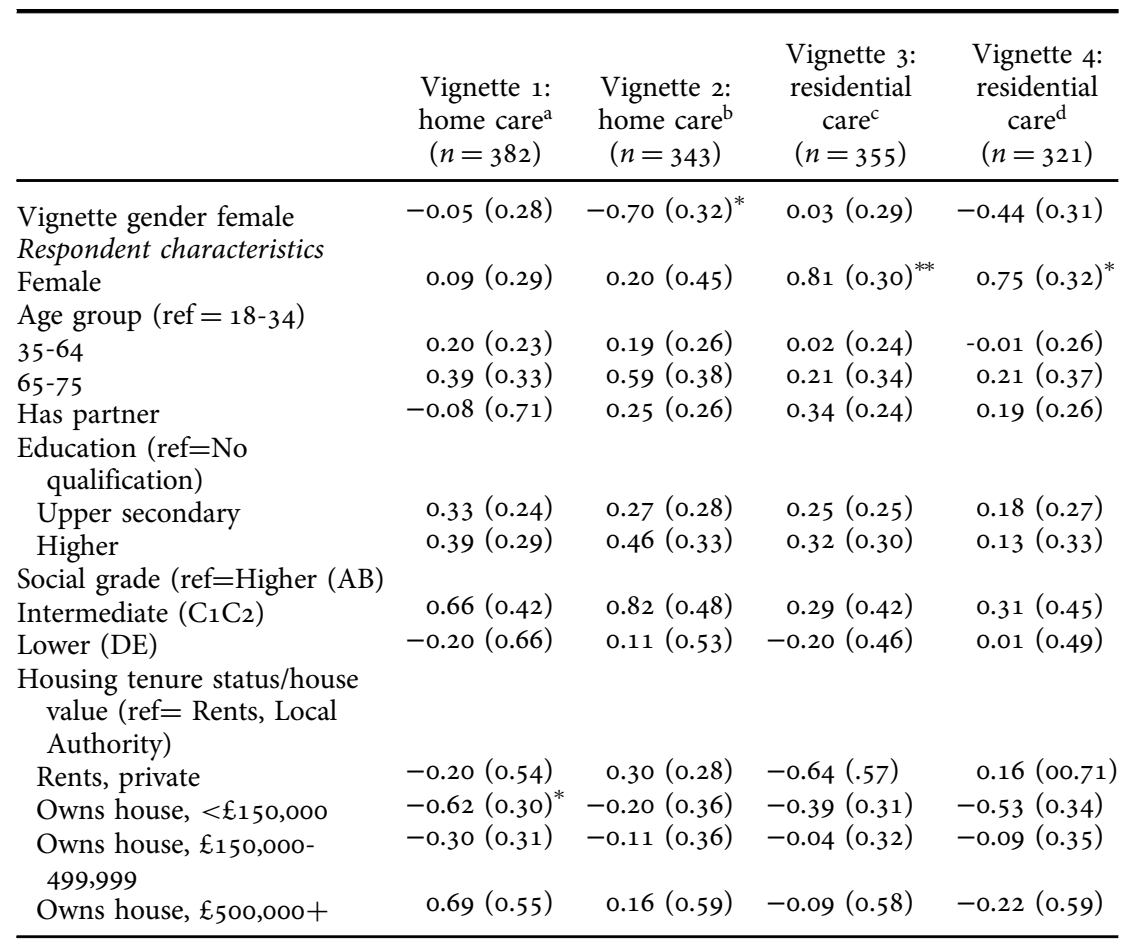

${ }^{a}$ Vignette 1: paying for home care cost of $£_{22}$ /week at varying levels of savings

${ }^{b}$ Vignette 2: paying for home care cost of $£_{22}$ /week at varying levels of income

${ }^{c}$ Vignette 3: paying for residential care cost of $\mathfrak{k}_{75}$ /week at varying levels of house value

${ }^{\mathrm{d} V i g n e t t e} 4$ : paying for residential care cost of $\mathfrak{E}_{75}$ o/week at varying levels of income ${ }^{*} p<0.05$,

${ }^{* *} p<0.01,{ }^{* * * *} p<0.001$

On the other hand, there was uncertainty about what the upper lifetime limit should be, with nearly half of respondents stating that they did not know at which level the state should take responsibility for payment. This was the highest proportion of 'don't knows' in the survey. Nevertheless, responses to this question about an upper limit to user contributions suggest reasonably strong support for the proposal of a lifetime cap on individuals' liability to meet care costs (CFCS, 2011).

Another important finding in our study was that similar views were held about paying for home care and for care home costs, but these views could be examined only where the service user had modest income and savings and owned a home of below average value. Those who considered that the state 
should pay all the costs or that the user should pay all the costs of home care were very likely to choose the same response for paying for residential care. Among those who proposed that home care costs be shared between the individual and the state, but care home costs should not be shared, there was a slight preference for the individual rather than the state to meet care home costs.

There was a slight effect of vignette gender in favour of a higher user contribution by males than by females to meeting care costs. The wording in the vignettes was identical except for the names referring to a female or male. The results suggest that people may make different assumptions about an individual's circumstances based on the gender of the vignette character. This seemed to apply especially to the cases with low income (state pension only), which raises interesting questions about why respondents might consider that women reliant on a state pension should receive state support more than men in the same situation. Interestingly, a previous survey found that women were more likely than men to agree that it was their responsibility to contribute to their care costs but were more concerned about meeting these costs (Ipsos Mori, 2015).

Our findings are broadly consistent with previous studies that found that the majority of the public believe that social care users should be responsible for at least some of the costs of their care (Bottery et al., 2018; Ipsos Mori, 2013; Wood and Vibert, 2017). However, we found that less than one-quarter of people considered that the state should be responsible for paying all the costs of care. This is lower than the proportions of 36 per cent to 50 per cent found in previous studies (Ipsos Mori, 2013; Tian, 2014; Wood and Vibert, 2017). This difference in findings may be due to differences in methods, since our study asked respondents to engage with realistic vignettes where the individual's income, wealth, care needs and social care costs were clearly stated. This use of vignettes may help respondents by rendering the questions more specific and easier to relate to. Another possible reason is that our study, unlike earlier studies, focused solely on paying for social care. The juxtaposition of health and social care in some of the other studies may have prompted more respondents to state that social care should resemble NHS care in being free at the point of use. The potential reasons for the difference in findings between our study and other studies is discussed in more detail elsewhere (Read et al., 2021).

One of the strengths of this study was the use of detailed vignettes to elicit respondents' views about service users with specific needs and resources and, in particular, whether and, if so how, the responsibility for paying for social care should vary with users' savings, income and housing assets, as in the current system. Using vignettes made it possible to present 'real world' scenarios and reduce the risk of poorly informed responses. Our study demonstrates that the use of vignettes for this topic can work well, even online (Erens et al., 2020). For example, the rate of declining to answer questions or responding 
'don't know' was fairly low, particularly in the online survey, suggesting that the sample found the vignette-based questions manageable and felt able and willing to address them.

The proportion of the sample responding 'don't know' was lower for the online survey (between 7 and 8 per cent for the questions on the vignettes) than for the interview survey (between 15 and 27 per cent). Since the questions are not straightforward and require some thought, it is not surprising that a proportion of respondents felt unsure about who should pay for care under different circumstances. Why the 'don't know' rate was higher for the interview survey is unclear. It could reflect greater uncertainty among older people on the issue of paying for care. Another possibility is that, while respondents to the online survey had as much time as they wanted to answer each question, interview respondents may have felt that they should not delay the interviewer by pondering at length over the questions.

A limitation of the study is the slight over-representation of people with higher educational attainment in the online sample (Erens et al., 2020). As shown previously, people in higher social grades and with higher levels of education tend to be over-represented in voluntary online panels (Baker et al., 2010). For this reason, it is not recommended to use voluntary online panels when the study aim is to provide robust population-level estimates representative of the entire population, because of these and other potential selection biases in recruitment (Baker et al., 2010). We have shown that social grade and education can influence people's funding preferences (Erens et al., 2020), and this could have affected the estimates of who should pay in response to the vignettes. However, surveys using voluntary online panels can be useful for studies looking at how preferences vary according to different personal circumstances and socio-demographic characteristics as in the current analysis.

In addition, sample sizes in both surveys became quite small when divided into subgroups. While the proportion of 'don't know' responses was low for the core questions related to the vignettes, they were higher for the follow-on questions. A limitation of the comparison between residential care and home care contributions to costs is that the vignettes were always asked in the same order, with home care vignettes presented first. A limitation of the comparison between scenarios involving different levels of savings and scenarios involving different level of income is that, where different levels of savings (income) were presented, the level of income (savings) was held constant. Caution is therefore required when comparing views about use of savings to fund care with views about the use of income to fund care. We could not, however, have used many more vignettes: more vignettes would have increased the risk that respondents would either refuse to take part or give poor quality responses.

The study was unable to explore reasons underlying responses to vignettes such as why respondents thought care costs should or should not be shared 
between state and service user. Further research using vignettes or discrete choice experiment methods could help to explore these issues and further untangle the basis of people's priorities related to paying for care. We are undertaking further qualitative research to examine some of these issues.

Our findings highlight the complexities of public attitudes about social care funding and thus their subtle implications for any potential reforms, despite a large proportion of the public supporting at least some user contribution to social care costs. Apart from the lifetime cap on user charges noted above (CFCS, 2011), other reforms to social care funding have been proposed in England over the last two decades. For example, free personal care at the point of use, with a means test only for domestic help and general accommodation and living expenses in care homes, was recommended by a Royal Commission on Long Term Care (1999) and has recently re-entered the debate in England (Bushnell et al., 2018; House of Lords Economic Affairs Committee, 2019). A partnership arrangement with a set proportion of basic care funded by the state has also been proposed (HM Government, 2009). None of these proposals has been implemented in England, but the Government has announced the introduction of a cap on lifetime liability to meet care costs (HM Government, 2021).

Our findings can inform development of policies for reforming the system of financing social care in England in two ways. First, they provide an indication of how the public may be expected to view the reform options that policymakers may be considering. Second, they could help policymakers to explain the case for the policy options they decide to pursue and to frame the arguments in ways that might resonate better with the general public.

A key message from our study for policy development is that the majority of the public would support a reformed funding arrangement for social care where costs are shared between the state and service users. However, a majority would prefer that service users meet less than half of the costs of their care. This indicates a more generous means test than is currently in place in which fewer service users (if any) would be required to meet the full costs of their care without any limit or cap.

While this study was conducted in England, specifically to inform the continuing debate about reforming the system in England, it is likely to be of direct interest for other countries with similar systems, such as New Zealand, and more widely in terms of its contribution to understanding public views on how social care should be funded.

\section{Statement of conflict of interest}

The authors state that they have no conflict of interest. 


\section{Acknowledgements}

The authors would like to thank all those who gave up their time by completing the survey or taking part in the interviews for this project. We are also grateful to our colleagues at Kantar, Public Division, especially Emily Edwards-Hughes and Alice Fearn, for their help in the design and conduct of the survey. All the authors participated in development of the concept and approach, the interpretation of the findings and the drafting of the paper; and all approved the submitted version of the paper. BE led on detailed development of the survey questions and links with Kantar; and SR led on analysis of the data. This report is based on independent research commissioned and funded by the National Institute for Health Research (NIHR) Policy Research Programme through its core support to the Policy Innovation Research Unit (Project No: 102/0001). The views expressed are those of the authors and are not necessarily those of the NIHR or the Department of Health and Social Care. The NIHR played no role in the detailed design, execution, analysis, interpretation of data or writing of the study. The survey was approved by the LSHTM Observational Research Ethics Committee (Ref 16186).

\section{References}

Baker, R., Blumberg, S. J., Brick, M. J., Couper, M. P., Courtright, M., Dennis, J. M., Dillman, D., Frankel, M. R., Garland, P., Groves, R. M., Kennedy, C., Krosnick, J., Lee, S., Lavrakas, P. J., Link, M., Piekarski, L., Rao, K., Rivers, D., Thomas, R. K. and Zahs, D. (2010), Report on Online Panels. Prepared for the American Association for Public Opinion Research (AAPOR) Executive Council. https://www.aapor.org/Education-Resources/Reports/ Report-on-Online-Panels

Baxter, K., Heavey, E. and Birks, Y. (2019), Choice and control in social care: Experiences of older self-funders in England. Social Policy and Administration 2020; 54:460-474, https://onlinelibrary.wiley.com/doi/10.1111/spol.12534

Bethlehem, J. (2010). 'Selection bias in web surveys'. International Statistical Review 78(2): $161-188$

Bottery, S., Varrow, M., Thorlby, R. and Wellings, D. (2018), A fork in the road: next steps for social care funding reform. London: The King's Fund and Health Foundation. www. kingsfund.org.uk/publications/fork-road-social-care-funding-reform

Burkitt, R., Kate Duxbury, K., Evans, H., Ewbank, L., Gregory, F., Hall, S., Wellings, D. and Wenzel, L. (2018), The public and the NHS: what's the deal? London: The King's Fund. www.kingsfund.org.uk/publications/public-and-nhs-whats-the-deal [Accessed 29 April 2020]

Bushnell, J., Mitchell, R. and Seymour, C. (2018), Free personal care: how to eliminate catastrophic costs. Independent Age. https://www.independentage.org/free-personal-carehow-to-eliminate-catastrophic-costs

CFCS (2011), Fairer care funding: report of the Commission on Funding of Care and Support, July 2011, https://webarchive.nationalarchives.gov.uk/20130221121529/https://www.wp. dh.gov.uk/carecommission/files/2011/o7/Fairer-Care-Funding-Report.pdf

Charlesworth, A., Anderson, M., Donaldson, C., Johnson, P., Knapp, M., McGuire, A., McKee, M., Mossialos, E., Smith, P., Street, A and Woods, M. (2021). What is the right level of spending needed for health and care in the UK? The Lancet Vol 397, Issue 10288, 22-28 May 2021, pp 2012-2022

Charlesworth, A. and Johnson, P. (2018), Securing the future: funding health and social care to the 2030s. London: Institute for Fiscal Studies. https://www.ifs.org.uk/uploads/ publications/comms/R143_Chapter1.pdf [Accessed 29 April 2020]

Comas-Herrera, A., Butterfield, R., Fernández, J.L., et al. (2012). 'Barriers and Opportunities for Private Long-Term Care Insurance in England: What Can We Learn from Other 
Countries'. In A. McGuire \& J. Costa-Font, eds. Elgar Edward LSE Companion to Health Policy, London, UK: Elgar Edward.

Curry, N. (2019). What can England learn from the long-term care system in Germany? Research report, Nuffield Trust. https://www.nuffieldtrust.org.uk/files/2019-09/ 1568207938_ltci-germany-br1924-web.pdf.

Curry, N., Castle-Clarke, S., and Hemmings, N. (2018). What can England learn from the longterm care system in Japan? Research report, Nuffield Trust. https://www.nuffieldtrust. org.uk/files/2018-05/1525785625_learning-from-japan-final.pdf.

Curry, N. and Oung, C. (2021), Fractured and forgotten? The social care provider market in England, research report April 2021, Nuffield Trust https://www.nuffieldtrust.org.uk/ files/2021-04/nuffield-trust-social-care-provider-market-web1.pdf

Department of Health and Social Care (2018), Care and support statutory guidance. https:// www.gov.uk/government/publications/care-act-statutory-guidance/care-and-supportstatutory-guidance, updated 2 March 2020 [Accessed 30 April 2020].

Dixon, J., Trathen, A., Wittenberg, R., Mays, N., Wistow, G. and Knapp, M. (2019), Funding and planning for social care in later life: a deliberative focus group study. Health \& Social Care in the Community, 27 e687-e696

Erens, R., Read, S., Knapp, M., Wistow, G., Wittenberg, R. and Mays, N. (2020), Using vignettes to examine preferences for paying for long-term social care in online and interview surveys. Social Research Practice 9, 17-40. https://the-sra.org.uk/common/Uploaded \%2ofiles/SRA\%2ojournal\%2ospring\%202020.pdf

Fernández, J. L. and Forder, J. (2015), Local variability in long-term care services: local autonomy, exogenous influences and policy spillovers. Health Economics, 24 (S1). pp. 146-157

Forder, J. and Fernández, J. L. (2009), Analysing the costs and benefits of social care funding arrangements in England: technical report. PSSRU Discussion Paper 2644. London: Personal Social Services Research Unit. http://eprints.lse.ac.uk/24977/1/Analysing_the_ costs_and_benefits_of_social_care_funding_arrangements_in_England.pdf [Accessed 29 April 2020]

Foster, D. (2021), Reform of adult social care funding: developments since July 2019 (England). House of Commons Library briefing paper 8001, 14 May 2021, https:// researchbriefings.files.parliament.uk/documents/CBP-8001/CBP-8001.pdf

Gregory, S. (2014), Attitudes to health and social care: review of existing research. London: The King's Fund. https://www.kingsfund.org.uk/sites/default/files/media/commissionbackground-paper-attitudes-health-social-care.pdf

Hewitson, B., Seale, B. and Joyce, L. (2011), Public engagement exploring care and support funding options: TNS-BMRB report of findings in Fairer care funding: supporting documents. London: HM Government. http://webarchive.nationalarchives.gov.uk/20130221130239/

Hirsch, O., Hauschild, F., Schmidt, M. H., Baum, E., and Christiansen, H. (2013), Comparison of web-based and paper-based administration of ADHD questionnaires for adults. Journal of Medical Internet Research, 15(3):e47 (doi: 10.2196/jmir.2225)

HM Government (2009), Shaping the future of care together. Cm 7673. London: The Stationery Office. https://www.gov.uk/government/publications/shaping-the-future-of-care-together

HM Government (2021), Build Back Better: our plan for health and social care, CP506 https:// assets.publishing.service.gov.uk/government/uploads/system/uploads/attachment_data/ file/1015736/Build_Back_Better-_Our_Plan_for_Health_and_Social_Care.pdf

House of Lords Economic Affairs Committee (2019), Social care funding: time to end a national scandal, 7th Report of Session 2017-19, HL Paper 392.

Ipsos Mori (2013), Public Perceptions of the NHS and Social Care. London: Department of Health. https://www.ipsos.com/ipsos-mori/en-uk/public-perceptions-nhs-and-socialcare-survey-2

Ipsos Mori (2015), Public Perceptions of the NHS and Social Care. London: Department of Health. https://assets.publishing.service.gov.uk/government/uploads/system/uploads/ attachment_data/file/444783/NHS_tracker_acc.pdf 
Ipsos Mori (2018), Understanding public attitudes to social care funding reform in England. Report prepared for the Health Foundation. London: Health Foundation. https:// www.ipsos.com/ipsos-mori/en-uk/understanding-public-attitudes-social-care-fundingreform-england

Kingston, A., Comas-Herrera, A. and Jagger, C. for the MODEM project (2018a) Forecasting the care needs of the older population in England over the next 20 years: estimates from the Population Ageing and Care Simulation (PACSim) modelling study. Lancet Public Health, 3, 9, e447-e455

Kingston, A., Robinson, L., Booth, H., Knapp, M. and Jagger, C. for the MODEM project (2018), Projections of multi-morbidity in the older population in England to 2035: estimates from the population ageing and care simulation (PACSim) model. Age and Ageing, $47,374-80$.

Office for National Statistics (2019), Living longer: is age 70 the new age 65? Available at: https://www.ons.gov.uk/peoplepopulationandcommunity/birthsdeathsandmarriages/ ageing/articles/livinglongerisage7othenewage65/2019-11-19

Oorschot, W. (1999). Targeting welfare: on the functions and dysfunctions of means testing in social policy. In: Townsend, P., Gordon, D. (eds.), World Poverty: New Policies to Defeat and Old Enemy. Policy Press, Bristol, pp. 171-193.

Overton, L. and Fox O’Mahony, L. (2017), Understanding Attitudes to Paying for Care amongst Equity Release Consumers: citizenship, solidarity and the "hardworking homeowner." Journal of Social Policy, 46, 49-67.

Price, D., Bisdee, D., Daly, T., Livsey, L. and Higgs, P. (2014), Financial planning for social care in later life: the "shadow" of fourth age dependency. Ageing and Society, 34, 388-410.

Prior, D. (2015), Cap on care costs, parliamentary statement made on 17 July 2015, https:// questions-statements.parliament.uk/written-statements/detail/2015-07-17/HLWS135

Read, S., Erens, B., Wittenberg, R., Wistow, G., Dickinson, F., Knapp, M., Cyhlarova, E. and Mays, N. (2021), Public preferences for paying for social care in later life in England: A latent class analysis. Social Science \& Medicine, 274, p.113803.

Royal Commission on Long Term Care (1999), With Respect to Old Age. Cm 4192. London: The Stationery Office. https://webarchive.nationalarchives.gov.uk/20131205101144/ http://www.archive.official-documents.co.uk/document/cm41/4192/4192.htm [Accessed 5 May 2020]

Scottish Government (2019). Free personal and nursing care questions and answers. https:// www.gov.scot/publications/free-personal-nursing-care-qa/

Sussex, J., Burge, P., Lu, H., Exley, J. and King, S. (2019), Public acceptability of health and social care funding options. London: The Health Foundation. https://www.health.org. uk/publications/public-acceptability-of-health-and-social-care-funding-options

Tian, Y. (2014), Who should pay for social care services? Blog. The King's Fund website. www. kingsfund.org.uk/blog/2014/o1/who-should-paysocial-care-services

Titmuss, R. (1968). Commitment to Welfare. Allen and Unwin, London.

Townsend, P. (2002), The Restoration of Universalism, The Rise and Fail of Keynesian Influence on Social Development Policies. Geneva, Switzerland: Social Policy in a Development, The United Nations Research Institute for Social Development (UNRISD).

Wanless, D., Forder, J., Fernández, J. L., Poole, T., Beesley, L., Henwood, M. and Moscone, F. (2006). Wanless social care review: securing good care for older people, taking a longterm view. King's Fund, https://www.kingsfund.org.uk/sites/default/files/field/field_ publication_file/securing-good-care-for-older-people-wanless-2006.pdf

Wood, C. and Vibert, S. (2017), A Good Retirement: public attitudes to the role of the state and the individual in achieving financial security in later life. London: Demos. www.demos.co. uk/wp-content/uploads/2017/12/ 